\title{
Incidence of Medication Error in Critical Care Unit of a Tertiary Care Hospital: Where Do We Stand?
}

Anand Bhutada

\author{
Indian Journal of Critical Care Medicine (2020): 10.5005/jp-journals-10071-23609
}

To err is human.

Globally healthcare system is recently witnessing a big technological revolution. Despite all efforts, medical errors (ME) are ubiquitous.

The National Coordinating Council for Medication Error Reporting and Prevention has defined medication error (ME) as "any preventable event that may cause or lead to inappropriate medication use or patient harm, while the medication is in the control of the healthcare professional, patient, or consumer". ${ }^{1-3}$

In hospitals, errors occur in every step of medication use process starting from procuring the drug to prescribing, transcribing, dispensing, administering, and monitoring its effect. ${ }^{2}$ Annually 7,000 mortalities have been reported due to medication errors. ${ }^{3}$ In India, the medication errors and medication-related problems are mainly due to irrational use of medications. ${ }^{4,5}$ According to a recent finding, the incidence of adverse drug events was as high as $82 / 1,000$ prescriptions in Delhi, and the national figures report up to 5.2 million medical errors annually. ${ }^{4,5}$

Errors can happen due to lack of knowledge, poor performance, and psychological lapses. ${ }^{6}$ The pharmacists do play an important role along with physicians, nurses, and administrators to examine and improve healthcare system in order to ensure the patient safety. ${ }^{7}$

A prescription is information from a prescriber to dispenser. The most important requirement is that it should be legible and it should have basic information. ${ }^{8}$ A multidisciplinary approach is required to solve the problem of medication errors with no blame. $^{9}$

There is a need for the regulatory agencies to develop a standard prescription format and implement it throughout the country.

\section{WhO Prescription Writing Guidelines}

- Name, address, telephone number of the prescriber

- Date

- Generic name of the drug and strength

- Dosage form and total amount

- Label: instructions and warning

- Name, address, and age of the patient

- Signature or initials of prescriber

It was observed from recent studies that medical errors increase with polypharmacy (more number of medicines prescribed), looking-alike sounding-alike (LASA) drugs, elderly patients, emergency care, busy OPDs, night shifts, communication barriers, and illegible hand writing. ${ }^{10}$

Department of Pediatric Intensive Care, Nelson Mother and Child Care Hospital, Nagpur, Maharashtra, India

Corresponding Author: Anand Bhutada, Department of Pediatric Intensive Care, Nelson Mother and Child Care Hospital, Nagpur, Maharashtra, India, Phone: +91 9922066527, e-mail: drbhutada@ gmail.com

How to cite this article: Bhutada A. Incidence of Medication Error in Critical Care Unit of a Tertiary Care Hospital: Where Do We Stand? Indian J Crit Care Med 2020;24(9):753-754.

Source of support: Nil

Conflict of interest: None

Following strategies are summarized to minimize medical errors in hospital settings: ${ }^{11}$

\begin{tabular}{ll}
\hline Stage & Safety strategy \\
\hline Prescribing & 1. Avoid unnecessary medications by adhering to \\
conservative prescribing principles \\
2. Computerized provider order entry, especially \\
when paired with clinical decision-support \\
systems \\
3. Medication reconciliation at times of transitions \\
in care \\
Computerized provider order entry to eliminate \\
handwriting errors \\
Transcribing \\
Clinical pharmacist to oversee medication \\
dispensing process \\
Use of "tall man"lettering and other strategies to \\
minimize confusion between look-alike, sound- \\
alike medications \\
Automated dispensing cabinets for high-risk \\
medications \\
1. Adherence to the "five rights" of medication \\
safety (administering the right medication, in \\
the right dose, at the right time, by the right \\
route, to the right patient) \\
2. Barcode medicine administration to ensure \\
medications are given to the correct patient \\
3. Minimize interruptions to allow nurses to \\
administer medications safely \\
4. Smart infusion pumps for intravenous infusions \\
5. Multicompartment medication pumps for \\
patients taking multiple medications in \\
ambulatory or long-term care settings \\
6. Patient education and revised medication \\
labels to improve patient comprehension of \\
administration instructions.
\end{tabular}

(0) The Author(s). 2020 Open Access This article is distributed under the terms of the Creative Commons Attribution 4.0 International License (https://creativecommons. org/licenses/by-nc/4.0/), which permits unrestricted use, distribution, and non-commercial reproduction in any medium, provided you give appropriate credit to the original author(s) and the source, provide a link to the Creative Commons license, and indicate if changes were made. The Creative Commons Public Domain Dedication waiver (http://creativecommons.org/publicdomain/zero/1.0/) applies to the data made available in this article, unless otherwise stated. 
To summarize, ME is an adverse preventable event that happens due to the inappropriate use of medication that leads to patient harm. Such events may be related to professional practice, healthcare products, procedures, and systems including prescribing, communication, product labeling, packaging, and nomenclature, compounding, dispensing, distribution, administration, education, monitoring, and use. A major ME is the one that results in either permanent harm or transfer to the intensive care units or death. When an error is identified, it shall be reported immediately. It must also be nonpunitive so that staff is not afraid of repercussions and report the same. An error shall be reported to the concerned authority immediately. Involvement of a clinical pharmacist should be considered in minimizing medical errors in hospitals. Principles of simulation techniques can be utilized like closed loop communication, use of visual aids, and call for help and alike to minimize MEs. Institutions should identify a list of high-risk medications. This list could include all the drugs that have the propensity to cause serious harm. These drugs should be stored separately, with distinctly identified colored tapes. Use of medication in extremes of age and vulnerable populations should also be addressed separately during safety related to drug administration. A continuous surveillance system must be there in each hospital to monitor and report MEs. A root cause analysis shall be done for all serious MEs and solutions to be implemented accordingly.

\section{References}

1. Goulding PM. Prevention of Medical Errors (2016).
2. Aspeden P, Wolcot JA, Palugod RL, Bastein T. Preventing Medication Errors Institute of medicine (2016) Brief Report in July 2006.

3. Hinojosa-Amaya JM, Rodríguez-García FG, Yeverino-Castro SG, Sánchez-Cárdenas M, Villarreal-Alarcón MÁ, Galarza-Delgado DÁ. Medication errors: electronic vs. paper-based prescribing. Experience at a tertiary care university hospital. J Eval Clin Pract 2016;22(5):7 51-754. DOI: 10.1111/jep.12535.

4. Agrawal P, Sachan A, Singla RK, Jain P. Statistical analysis of medical errors in Delhi, India. Indo Global J Pharm Sci 2012;2:88-97.

5. ETHealthworld.com 5.2 million medical errors are happening in India annually: Dr Girdhar J. Gyani - ET HealthWorld. [online].

6. Hugar SM, Suganya M, Vikneshan M, Kiran K. Medication errors and its implications in pediatric dentistry. Indian J Oral Sci 2014;5(1):27-32. DOI: 10.4103/0976-6944.129946.

7. Billstein-Leber M, Carrillo CJD, Cassano AT, Moline K, Robertson JJ. ASHP guidelines on preventing medication errors in hospitals. Am J Hosp Pharm 1993;50:305-314.

8. Roy V, Gupta P, Srivastava S. Medication errors: causes and prevention. Health Adm 2005;29:60-64.

9. De Vries TPGM, Henning RH, Hogerzeil HV, Fersle DA. Guide to good prescribing: a practical manual. Geneva World Health Org 1994;94:51-55.

10. Hickner J, Zafar A, Kuo GM, Fagnan LJ, Forjuoh SN, Knox LM, et al. Field test results of a new ambulatory care medication error and adverse drug event reporting system-MEADERS. Ann Fam Med 2010;8(6):517-525. DOI: 10.1370/afm.1169.

11. Pramod Kumar M, Prathibha D, Ravi Teja G, Keerthana K. Assessment of medication errors in tertiary care hospital. Int J Pharm Sci Rev Res 2020;61(1):1-8. 